\title{
Politically Feasible Emissions Targets to Attain 460 ppm CO2 Concentrations
}

\author{
Valentina Bosetti, FEEM, Milan, and \\ Jeffrey Frankel, Harvard University
}

CID Working Paper No. 226

October 2011

C Copyright 2011 Bosetti, Frankel and the President and Fellows of Harvard College

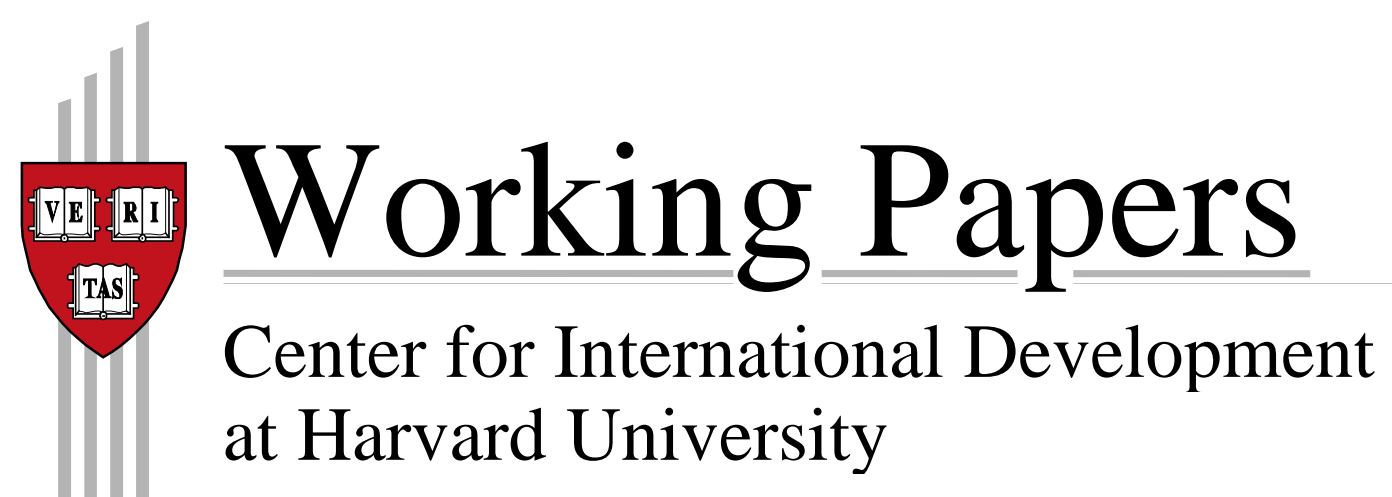


revised October 31, 2011

Politically Feasible Emissions Targets to Attain 460 ppm CO2 Concentrations

Valentina Bosetti, FEEM, Milan, and Jeffrey Frankel, Harvard University

Forthcoming, Review of Environmental Economics and Policy (Oxford University Press), Winter 2012. Bosetti received support from the Climate Impacts and Policy Division of the EuroMediterranean Center on Climate Change. Frankel received funding from the Sustainability Science Program which was then housed in the Center for International Development at Harvard University, supported by Italy's Ministry for Environment, Land and Sea. The article is revised from a 2009 paper written while

Bosetti was visiting at the Princeton Environmental Institute in the framework of cooperation between CMCC and PEI. The full November 2009 version of the paper, with appendix tables, is available under the title, "Global Climate Policy Architecture and Political Feasibility: Specific Formulas and Emission Targets to Attain 460 ppm CO2 Concentrations,” as FEEM Working Paper 92.2009 and NBER Working Paper 15516.

\begin{abstract}
$\underline{\text { Abstract }}$
A new climate change treaty must address three current gaps: the absence of emissions targets extending far into the future, the absence of participation by the United States, China, and other developing countries, and the absence of reason to expect compliance. Moreover, to be politically acceptable, a post-Kyoto treaty must recognize certain constraints regarding country-by-country economic costs. This article presents a framework for assigning quantitative emissions allocations across countries, one budget period at a time, through a two-stage plan: (i) China and other developing countries accept targets at business-as-usual (BAU) levels in the coming budget period, and, during the same period, the US agrees to cuts below BAU; (ii) all countries are asked to make further cuts in the future in accordance with a formula which includes a Progressive Reductions Factor, a Latecomer Catch-up Factor, and a Gradual Equalization Factor. An earlier proposal (Frankel 2009) for specific parameter values in the formulas achieved the environmental goal that CO2 concentrations plateau at $500 \mathrm{ppm}$ by 2100 . It met our political constraints by keeping every country's economic cost below thresholds of $Y=1 \%$ of income in Present Discounted Value, and $X=5 \%$ of income in the worst period. The framework proposed in this article attains a stricter concentration goal of $460 \mathrm{ppm} \mathrm{CO2,}$ but only by loosening the political constraints.

JEL classification number: Q54

Keywords: China, concentrations, Copenhagen, costs, developing countries, emissions, equity, global climate, global warming, greenhouse gas, international, Kyoto, political, targets, treaty
\end{abstract}




\section{Introduction}

Negotiators for the United Nations Framework Convention on Climate Change (UNFCCC) have been hoping to achieve a successor to the Kyoto Protocol and to set emissions targets after 2012. Although there was some progress at the meetings in Copenhagen in 2010 and Cancun in 2011, the road to a post-Kyoto treaty has been blocked by a seemingly insurmountable obstacle: the United States, which until recently was the world's largest greenhouse gas (GHG) emitter, is at loggerheads with China (the world’s new largest emitter), India, and other developing countries.

On one side, the US Congress has made it clear that it will not impose quantitative limits on US GHG emissions if it appears that emissions from China, India, and other developing countries will continue to grow unabated. Indeed, this is the reason the Senate refused to ratify the Kyoto Protocol in the first place. Why, the Senate asks, should US firms bear the economic cost of cutting emissions if energy-intensive activities such as aluminum smelters and steel mills will just migrate to countries that have no caps and therefore have cheaper energy - the problem known as leakage - and global emissions will continue their rapid rise?

On the other side, the leaders of India and China have made their position just as clear: they are unalterably opposed to cutting emissions unless the United States and other rich countries cut theirs first. They argue that poor countries should not be denied their turn at economic development. After all, the industrialized countries created the problem of global climate change, while developing countries are responsible for only about 20 percent of the carbon dioxide $\left(\mathrm{CO}_{2}\right)$ that has accumulated in the atmosphere 
from industrial activity over the past 150 years. India points out that Americans emit more than ten times as much $\mathrm{CO}_{2}$ per person as they do.

Fortunately, there might be a politically feasible solution to the apparently irreconcilable differences between the US and the developing countries regarding binding quantitative targets. What is needed is a specific framework for setting the actual numbers that future signers of a post-Kyoto treaty might realistically be expected to adopt as their emission targets. Such an agreement would include a commitment by the United States to join Europe in adopting serious emission targets, while simultaneously, China, India, and other developing countries would agree to a path that immediately imposes on them binding emission targets - but in the first period these targets would simply follow the so-called business-as-usual (BAU) path. ${ }^{1}$

Of course, an effective environmental solution also requires that in future years China and the other developing countries make cuts below their BAU path, and eventually make cuts in absolute terms as well. The negotiation process would become easier over time as participants gained confidence in the framework. The point is that the developing countries can and should be asked to make cuts in the future that do not differ in nature from those made by Europe, the United States, and others who have gone before them, taking due account of differences in income. More specifically, emissions targets should be determined by formulas that: (i) give lower-income countries more time before they start to cut emissions, and (ii) lead to a gradual convergence across countries

\footnotetext{
${ }^{1}$ BAU is generally defined as the path of increasing emissions that countries would follow in the absence of an international agreement. It is a counterfactual that can be generated through models on the basis of projections of such main drivers as population and GDP growth. One must recognize, however, substantial uncertainty over the BAU path of emissions..
} 
of emissions per capita over the course of the century, while (iii) not rewarding countries for joining the agreement late.

There are currently many proposals on the table for a post-Kyoto climate change regime, even if one considers only those proposals that accept the basic Kyoto approach of quantitative, national-level limits on GHG emissions accompanied by international trade in emissions permits (i.e., cap and trade). However, the Kyoto targets applied only to the budget period 2008-2012, and only to a minority of countries (in theory, the industrialized countries). The current challenge is to extend quantitative emissions targets through the remainder of the century and to other countries - especially the United States, China, and other developing countries.

Virtually all the existing proposals for a post-Kyoto agreement are based on scientific environmental objectives (e.g., stabilizing atmospheric $\mathrm{CO}_{2}$ concentrations at $380 \mathrm{ppm}$ in 2100), ethical/philosophical considerations (e.g., the principle that every individual on earth has equal emission rights), or economic benefit-cost analyses (weighing the economic costs of abatement against the long-term environmental benefits). Important examples of the science-based approach, the benefit-cost-based approach, and the rights-based approach are, respectively, Wigley, Richels and Edmonds (2007), Nordhaus (1994, 2006), and Baer et al. (2008).

Only credible announcements of future cuts will send firms the long-term price signals and incentives needed to guide investment decisions today. Announcements of future cuts are credible only if they are also politically viable. In the real political world, no country - rich or poor - is likely to abide by targets in any given period that entail extremely large economic sacrifice, when there is the alternative of simply not 
participating in the system. Thus, rather than making sweeping proposals that assume otherwise, it is better to pursue the narrow thread of what is politically possible. This article, which is part of a symposium on the Post-Kyoto International Policy Architecture, ${ }^{2}$ proposes a framework for allocating quantitative emissions targets for all countries for the remainder of the century. This framework is intended to be more practical than other proposals because it addresses political considerations, rather than being based solely on science, ethics or economics. ${ }^{3}$

The article is organized as follows. In the next section we explain the motivation underlying our framework for setting emissions targets, beginning with a discussion of the tremendous political obstacles and then an overview of our proposed approach. The following section presents rules to guide the formulas for setting emissions targets. We next discuss specific post-Kyoto quantitative targets announced by several national leaders, which provide the basis for formulating reasonable targets for other countries in subsequent periods. This is followed by a discussion of the factors that need to be included in the formulas to ensure that the emissions targets for developing countries are "fair." Next we present the specific numerical emissions targets: that is, the paths that follow from the formulas for all countries and in all budget periods during this century. Finally, we estimate the economic and environmental effects of the proposed targets using the WITCH model, an energy-economy-climate model developed by the climate

\footnotetext{
${ }^{2}$ The other articles in this symposium are Cao (2012), Metcalf and Weisbach (2012), and Olmstead and Stavins (2012).

${ }^{3}$ Aldy, Barrett, and Stavins (2003) and Victor (2004) review a number of existing proposals. Numerous others have offered their own thoughts on post-Kyoto plans, at varying levels of detail, including Aldy, Orszag, and Stiglitz (2001); Barrett (2006); Nordhaus (2006); and Olmstead and Stavins (2006).
} 
change modeling group at Fondazione Eni Enrico Mattei (FEEM). ${ }^{4}$ The conclusions section discusses why the proposed framework is politically credible and identifies some areas for future research.

\section{Constraints and a Proposed Solution for a Post-Kyoto Framework}

In 1997, the industrialized countries agreed to quantitative emissions targets for the Kyoto Protocol's first budget period. So we know that in some sense it is possible to set quantitative emissions targets.

At subsequent multilateral venues such as the UNFCCC meeting in Bali (2007) and the Group of Eight (G8) meeting in Hokkaido (July 2008), world leaders agreed on a broad long-term goal of cutting total global emissions in half by 2050. At a meeting in L'Aquila, Italy, in July 2009, the G8 leaders agreed to an environmental goal of limiting the global temperature increase to $2^{\circ} \mathrm{C}$, which corresponds roughly to a GHG concentration level of $450 \mathrm{ppm}$ (or approximately $380 \mathrm{ppm}$ for CO2 alone). However, these meetings did not come close to producing an agreement on who will cut how much. Nor did they result in an agreement on multilateral targets over a time horizon that is sufficiently short to ensure that the national leaders negotiating the agreements will likely still be alive when the abatement commitments come due. To quote Al Gore (1993, p.353), "politicians are often tempted to make a promise that is not binding and hope for

\footnotetext{
${ }^{4}$ See http://www.witchmodel.org/.
} 
some unexpectedly easy way to keep the promise.” Thus, the aggregate targets endorsed so far cannot be viewed as being anything more than aspirational.

Moreover, no enforcement mechanism has been developed that both has sufficient teeth and is acceptable to UNFCCC member countries. Given the importance countries place on national sovereignty, it is unlikely that this situation will change any time soon. Hopes must rest instead on weak enforcement mechanisms such as the power of moral suasion, international opprobrium, and, possibly, trade measures. We believe it is safe to say that in the event of a clash between such weak enforcement mechanisms and the prospect of a large economic loss to a particular country, aversion to the latter would overpower dislike of the former.

\section{A workable successor to Kyoto}

Unlike the Kyoto Protocol, the framework proposed here seeks to bring all countries into a realistic international policy regime that looks far into the future. We recognize, however, that it is not possible to predict a century-long horizon with as much precision/certainty as a five- or ten-year horizon, and acknowledge that fixing precise numerical targets a century ahead is impractical. Rather, what we need is a century-long sequence of negotiations, which fits within a common institutional framework that gains credibility as it goes along. Such a framework must have enough continuity so that success in the early phases builds participants' confidence in each others' compliance commitments and in the fairness, viability, and credibility of the process. Yet the framework must also be flexible enough to accommodate the unpredictable fluctuations in economic growth, technology development, climate, and political sentiment that will 
inevitably occur. Only by striking the right balance between continuity and flexibility can we hope that such a framework for addressing climate change will last a century or more.

\section{Recognizing political constraints}

Our proposed framework recognizes five political constraints:

1. The United States will not commit to quantitative targets unless China and other major developing countries commit to quantitative targets at the same time. (This proposition leaves open the initial level and future path of the targets.) A plan will be considered unacceptable to the United States if it allows the less developed countries to exploit their lack of GHG regulation for "competitive advantage” at the expense of the participating countries' economies and leads to emissions leakage at the expense of the environmental goal.

2. China, India, and other developing countries will not make sacrifices they view as

a. fully contemporaneous with rich countries,

b. different in character from those made in the past by richer countries,

c. preventing them from industrializing,

d. failing to recognize that richer countries should be prepared to make greater economic sacrifices to address the problem than developing countries, or

e. failing to recognize that the rich countries have benefited from an unfair advantage in being allowed to achieve levels of per capita emissions that are far above those of the poor countries. 
3. In the short run, emissions targets for developing countries must be calculated relative to current levels or BAU paths; otherwise the economic costs will be too great for developing countries to accept. However, in the longer run, no country should be rewarded for having "ramped up" emissions far above levels in an agreed-upon base year. The reference year agreed upon at Rio and Kyoto was 1990. Fairness considerations aside, if post-1990 increases are permanently "grandfathered," then countries that have not yet agreed to emissions cuts will have an incentive to ramp up emissions prior to joining the agreement. Of course, there was nothing "magical" about the year 1990. But, for better or worse, it is the year on which Annex I countries based their planning. ${ }^{5}$ If the international consensus base year were to shift from 1990 to 2005, our proposal would follow suit.

4. No country will accept a path of targets that is expected to cost it more than $Y$ percent of income throughout the $21^{\text {st }}$ century (in present discounted value). We try to limit $Y$ to 1 percent (as in Frankel, 2009).

5. No country will accept targets in any period that are expected to cost more than $X$ percent of income to achieve during that period; alternatively, even if targets were already in place, no country would actually abide by them in the future if it were found that the cost of doing so would exceed $X$ percent of income in any given period. We define income losses relative to what would happen if the agreement were to unravel. We try to limit $X$ to 5 percent as in Frankel (2009).

\footnotetext{
${ }^{5}$ Annex I is the UNFCCC name for the list of industrialized countries, including the transition economies of the former Soviet bloc, that were called upon to cut emissions under the Kyoto Protocol.
} 


\section{Addressing the constraints}

The first and second constraints alone would seem to add up to a hopeless stalemate. Nothing much can happen without the United States, but the United States will not commit to emissions target cuts unless China and other developing countries agree to start cutting emissions at the same time, and China will not start to cut emission unless the rich countries have gone first. However, there is a possible solution, an approach that satisfies all of the constraints: at the same time that the United States agrees to binding emissions cuts, China and other developing countries agree to a path that immediately imposes binding emissions targets on them - but in the early years these targets simply follow the BAU path.

Our proposed formulas for setting emissions targets do ask substantially more of the developing countries in later decades. But these formulas also follow basic notions of fairness by asking only for cuts that are analogous in magnitude to those made by countries which began abatement earlier and that make due allowance for developing countries' lower per capita income and emissions and their baseline of rapid growth. The outline for this approach was developed in earlier papers (Frankel, 1999, 2005, 2007; and Aldy and Frankel, 2004), which suggested that the formulas used to develop emissions targets incorporate at least four variables (1990 emissions, emissions in the year of the negotiation, population, and income). One might also include a few other, country-specific variables such as whether a country has coal or hydroelectric power though the 1990 level of emissions conditional on per capita income can largely capture such variables - and perhaps a dummy variable for the transition economies. 
We narrow down the broad family of emissions target formulas to a more manageable set, by the development of the three factors that are designed to capture widely held notions of "fairness" - a short-term Progressive Reductions Factor, a medium-term Latecomer Catch-up Factor, and a long-run Gradual Equalization Factor. They are defined below. Next we put them into operation to produce specific numerical targets for all countries, for all remaining five-year budget periods of the $21^{\text {st }}$ century. These targets are then fed into the WITCH model in order to identify their economic and environmental consequences. The framework is flexible so that one can adjust a parameter here or there - for example, if the economic cost borne by a particular country is deemed too high or the environmental progress deemed too low - without having to abandon the entire formulas framework.

Frankel (2009) showed that this approach could achieve an environmental goal of CO2 concentrations of $500 \mathrm{ppm}$ while satisfying the political constraints. However, far more aggressive cuts in emissions would be needed to attain the environmental goals of interest to policy makers. The plan presented in this article achieves a more ambitious goal of $460 \mathrm{ppm}$. What should be emphasized is that we take no position on the desirable stringency of the goal. The proposed formulae could be tuned to be in line with different environmental targets, however, a more ambitious goal requires relaxing the constraints on the allowable losses that each country would agree to suffer.

\section{Guidelines and Caveats for Setting Emissions Targets}


Under the proposed framework, all developing countries that have an ability to measure emissions would be asked to agree immediately to emissions targets that do not exceed their projected BAU baseline trajectory. ${ }^{6}$ The idea of developing countries committing to only BAU targets in the early decades will likely provoke strong objections from environmentalists and business interests in industrialized countries. But this commitment is more important than it sounds because, by preventing the developing countries from exploiting the opportunity to go above their BAU paths, it both precludes the carbon leakage that, absent such an agreement, would undermine the environmental goal, and ameliorates the competitiveness concerns of carbon-intensive industries in rich countries.

This approach also recognizes that it would be unreasonable to ask China to agree to substantial absolute cuts in the short term. Indeed, China might well object to being asked to take on any kind of binding targets at the same time as the United States. However, it is important to emphasize that China would actually gain from such an commitment to BAU levels because it would be able to sell emission permits at the same world market price as industrialized countries. In contrast, at present, China receives lower prices for lower-quality project credits under the Kyoto Protocol's Clean Development Mechanism.

How do we know that China would come out ahead under the framework proposed here? To accommodate its rapidly growing demand, China is currently building roughly 100 power plants per year. The cost of shutting down an alreadyfunctioning coal-fired power plant in the United States is far higher than the cost of

\footnotetext{
${ }^{6}$ Most countries in Africa would likely be exempted for several some years from any kind of commitment, even BAU targets, until they have better capacity to monitor emissions.
} 
building a new clean low-carbon plant in China to replace what might otherwise be a new dirty coal-fired plant. For this reason, when an American firm pays China to cut its emissions voluntarily, thereby obtaining a permit that the American firm can use to meet its emission obligations, both parties benefit, even in strictly economic terms. The environmental benefit is that China's emissions would (voluntarily) fall below its BAU commitment from the beginning. From a dynamic perspective, and given the long-lived nature of these plants, the incentive to shift towards a less carbon intensive capital stock will provide substantial additional benefits in ten or twenty years time, when China will also face a constraining target.

One must acknowledge that BAU paths are neither easily ascertained nor immutable. Countries may "high-ball" their BAU estimates in order to get more generous targets (though this may be difficult for those who have hitherto "low-balled" their claimed emissions path). Even assuming that estimates are unbiased, important unforeseen economic and technological developments could occur between 2010 and 2020 that will shift the BAU trajectory for the 2020s, for example. Any number of unpredictable events have already occurred in the years since 1990, including German reunification, the 1997-1998 East Asia crisis, the boom in the BRIC countries (Brazil, Russia, India, and China), the big rise in world oil prices, and the global financial crisis of 2008-09.

A first step toward addressing the practical difficulty of setting the BAU path would be to specify in the post-Kyoto treaty that estimates be generated by an independent international expert body rather than by national authorities. A second step would be to update the BAU paths every budget period. Allowing for periodic 
adjustments to the BAU baseline does risk undermining the incentive for carbon-saving investments, on the logic that such investments would reduce future BAU paths and thus reduce future target allocations. ${ }^{7}$ That is why the formula proposed here includes a Latecomer Catch-up Factor (see below), which rapidly diminishes the weight assigned to BAU after a few budget periods and instead tethers countries to their 1990 emissions levels in the medium run.

Under the proposed framework, countries are expected to agree to the second step - the setting of quantitative targets that entail specific cuts below BAU, at a time determined by their circumstances. In our initial simulations, the year chosen to require a commitment to cut emissions was generally determined by two thresholds: when a country’s average per capita income is projected to exceed $\$ 3000$ per year and/or when its per capita annual emissions are projected to approach 1 ton or more. We later found, however, that starting dates had to be further modified in order to satisfy our constraints regarding the distribution of economic losses.

The formulas approach proposed here assigns emissions targets in a way that is more sensitive to political realities than is typical of other proposed target paths, which are constructed either on the basis of a benefit-cost optimization or to deliver a particular environmental and/or ethical goal. Specifically, our numerical targets are based on (a) commitments that political leaders in various key countries had already proposed or adopted, as of 2009, and (b) formulas designed to assure latecomer countries that the emission cuts they are asked to make represent no more than their fair share, in that they correspond to the sacrifices that other countries have already made.

\footnotetext{
${ }^{7}$ This risk is the same as the risk of encouraging countries to ramp up their emissions, which we specified above would be axiomatically ruled out under any viable proposal.
} 
Our approach seeks to incorporate a further constraint arising in practical political realities. The constraint is that the emissions targets must not impose on any country an economic cost of more than $X \%$ of income, or else the country drops out. Dropping out could involve either explicit renunciation of the treaty or failure to meet the quantitative targets. Our assumption here is that under any such scenario, the whole scheme would eventually unravel. This unraveling would occur much earlier if private actors rationally perceived that at some point in the future major players would face such high economic costs that compliance would break down. In this case, the future carbon prices that are built into most models’ compliance trajectories would lack credibility, private actors today would not make investment decisions that reflect those projected future prices, and the effort would fail in the first period. Therefore, our approach to any scenario in which any major player is estimated to suffer economic losses greater than $X \%$ has been to go back and try to adjust some of the starting dates or other parameters of the emissions target formulas, so that economic losses are less than $X \%$.

We believe that these measures and mechanisms offer the greatest hope for achieving political viability: non-negative economic gains in the early years for developing countries, average costs below $Y$ percent of income over the course of the century, and protection for every country against losses as large, or larger than, $X$ percent of income in any period.

\section{Starting point for emissions target parameters: Near-term goals announced by national leaders}


The starting point for calculating the emissions targets proposed in our framework are the near-term goals that were announced by several national leaders in anticipation of the Copenhagen meeting. We are guided by these near-term commitments when choosing the parameters in our formulas in the next part of the paper. We work in terms of the 12 geographic units - countries and groupings of countries - of the WITCH model. We work in terms of five-year budget periods. We calculated country-specific or regionspecific numeric emission targets for every fifth year (e.g., 2015, 2020). For each fiveyear budget period, computations are based on the midpoint. For example the Kyoto period (2008-2012) is indicated by 2010.

\section{The European Union}

The European Union (EU) emissions target for 2008-2012 - 8 percent below 1990 levels - was agreed upon at Kyoto. ${ }^{8}$ In 2008, the EU committed to a target for the 20152020 budget period of 20 percent below 1990 levels, but said that if other countries joined in, it would cut emissions 30 percent below 1990 levels. ${ }^{9}$ Frankel (2009) used a target of 20\% below 1990 levels for the EU. Here we are more ambitious all around. Thus we set an EU target for the year 2020 of 30\% below 1990 levels. For the 20202025 period, and thereafter up to the eighth period (2045-2050), we have the EU targets progress in equal increments up to a 50 percent cut below 1990 levels. That is, emissions targets start at 35 percent below 1990 emissions and progress to 50 percent below 1990 emissions in the 2045-2050 period.

\footnotetext{
${ }^{8}$ Ellerman and Buchner (2008) show that the difference between allocations and emissions in 2005 and 2006 was probably in part attributable to abatement measures implemented in response to the positive price of carbon.

${ }^{9}$ Financial Times, Jan. 2, 2009, p.5.
} 


\section{Japan, Canada, and New Zealand}

For the Kyoto budget period, these three Pacific countries are assigned the goal of a 6 percent reduction below 1990 levels. Of all the Kyoto Protocol ratifiers, Canada is probably the farthest from achieving its Kyoto goal by 2012. In a concession to realism, we assume that these three countries do not reach the Kyoto target until 2012 (versus reaching it on average over the 2008-2012 budget period).

What about future budget periods? We focus here on Japan since it dominates this country grouping in terms of its economic size. In 2008, Japan’s then-Prime Minister, Yasuo Fukuda, announced a decision to cut Japan’s emissions 60-80 percent by mid-century, and, in 2009, his successor, Taro Aso, announced a plan to cut emissions 15 percent by 2020. ${ }^{10}$ In September 2010, the incoming Prime Minister, Yukio Hatoyama, declared a goal of cutting emissions to 25 percent below 1990 levels over the next 10 years, provided that other countries set similarly ambitious targets. ${ }^{11}$ Reflecting Japan’s announcements, our framework assumes that these three countries in aggregate cut their emissions 10 percent every five years between 2010 and 2050, computed logarithmically. The cumulative cuts are 80 percent in logarithmic terms (=8x10 percent), or 51 percent in absolute terms. In other words, by 2050, emissions fall to 49 percent of the year-2010 emissions level.

\section{The United States}

\footnotetext{
10 “Japan Pledges Big Cut in Emissions,” FT, June 10, 2008 p.6; and Associated Press, June 10, 2009, respectively.

${ }^{11}$ The Japan Times, September 8, 2009.
} 
In the United States, the Lieberman-Warner legislation, ${ }^{12}$ introduced in the Senate in 2007, would have begun by reducing emissions in 2012 to below 2005 levels and would have tightened the emissions cap gradually each year thereafter, so that by the year 2050 total emissions would be held to 30 percent of 2012 levels. ${ }^{13}$ Frankel (2009) assumed U.S. targets that cut the average annual emissions growth rate in half during the period 2008-2012 period, to 0.7 percent per year. ${ }^{14}$ At that point, emissions were assumed to plateau (growth was held to zero) for the period 2012-2017. Then the rest of the Lieberman-Warner formula was implemented, such that emissions in 2050 reach a level 67 percent below 1990 levels. ${ }^{15}$ Spread over 38 years, this approach implied sustained reductions of 2.6 percent per year on average, or 13 percent every five years. During the 2008 US presidential election campaign, the Republican candidate, John McCain advocated a 2050 emissions target of 60 percent below 1990 levels $^{16}$ while Barack Obama endorsed a more aggressive target of reducing 2050 emissions 80 percent below 1990 levels. ${ }^{17}$

The Waxman-Markey bill (the American Clean-Energy and Security Act, or ACES Act), which was passed by the House of Representatives in June 2009 (but not the Senate) was less aggressive with respect to the near-term targets. It specified that US emission allowances, or permits, would continue to grow at 3 percent per year from 2012 to 2017. On the other hand, the Waxman-Markey bill was aggressive with respect to the

\footnotetext{
12 S. 2191: America's Climate Security Act of 2007.

${ }^{13}$ In other words, a 70 percent reduction from emissions levels at the start date of the policy. Section 1201, pages 30-32. (The percentage is measured non-logarithmically.)

14 This is equivalent to 3.5 percent cumulatively, so that emissions in 2012 are 31.5 percent above 1990 levels, or 27 percent above 1990 levels logarithmically.

${ }^{15}$ Using the postponed base of the emissions plateau described above this is 98.5 percent below 2012 levels, logarithmically.

${ }^{16}$ Or 66 percent below 2005 levels. Washington Post, May 13, 2008, p. A14; and FT, May 13, 2008 , p.4.

${ }^{17}$ FT, Oct. 17, 2008.
} 
subsequent 33 years, assuming emissions reductions of about 5 percent per year from 2017 to 2050 (unless the price ceiling on allowances specified by an escape clause were to kick in). In this paper we use the numbers in the Waxman-Markey bill to represent the US position and to help determine the parameters for others who come to the table subsequently.

\section{Australia, South Korea and South Africa}

Until relatively recently, it seemed unlikely that any "non-Annex I" countries would commit to cuts below a BAU growth path within the next decade. But in 2008, the new president of South Korea, Myung-bak Lee, offered "a plan to cap emissions at current levels over the first Kyoto period.” ${ }^{18}$ This was an ambitious target in light of Korea's high economic growth rate. He also announced that, like the industrialized countries (a group to which Korea now belongs), "his country would slash emissions in half by 2050.”19 Korea’s emissions had risen 90 percent since 1990, and it is hard to imagine any country applying the brakes so sharply as to switch instantly from 5 percent annual growth to zero growth in emissions.

In the regional groupings of our model, South Korea is grouped with South Africa and Australia: all three are coal-dependent. South Africa proposed in 2008 that its emissions would peak by 2025 and begin declining by $2030 .^{20}$ But South Africa is considerably smaller than the other two members of this grouping.

\footnotetext{
18 “South Korea Plans to Cap Emissions,” International Herald Tribune, March 21, 2008.

19 “South Korea: Developing Countries Move Toward Targets,” Lisa Friedman, ClimateWire, Oct. 3, 2008.

${ }^{20}$ ClimateWire, Oct.3, 2008, op cit. Statements from environmental or foreign ministries do not necessarily carry a lot of weight, if they have not been vetted by finance or economics ministries, issued by heads of government or approved by parliaments. An example would be Argentina's announcement of a target in 1998.
} 
The Australian government has been reluctant to take strong actions on emissions reductions because the country is so dependent on coal. In 2008, however, then-PrimeMinister Kevin Rudd announced plans to cut Australia’s emissions to 60 percent below 2000 levels by $2050 .^{21}$ In 2009, the government set a target to cut emissions to 5 percent below 2000 levels by 2020 .

We have interpreted the Korean plan to flatten emissions as covering a period that extends over the next decade, so that in 2020 the level of emissions is the same as in 2005. We have further chosen to represent by this formulation the entire three-country grouping. (Korea is bracketed above by Australia and below by South Africa, in terms of per capita income and presumed obligation for early action.) We also use the Korean plan to help parameterize the formulas that are reasonable to ask of others who come later.

\section{China}

Getting China to agree to binding commitments is the sine qua non of any successful post-Kyoto plan. In August 2009, a top Chinese climate change policy-maker set a target for emissions to peak by 2050. Frankel (2009) assumed that China would start cutting emissions relative to BAU in 2030. But since the proposal in this paper assumes more aggressive cuts by the industrialized countries during this period, and the year-2100 goal of CO2 concentrations at $460 \mathrm{ppm}$ cannot be met without substantial effort by China, we now move up the date at which China begins to cut to 2025 .

\section{Other developing countries}

21 “FACTBOX - Greenhouse gas curbs from Australia to India,” Sept.5, 2008, Reuters. 
In mid-2009, Mexican President Felipe Calderon's environment minister, Juan Rafael Elvira, announced that the country was committing to reduce the country's greenhouse gas emissions by 50 million metric tons a year between 2009 and 2012, and by 50 percent below 2002 levels by $2050 .^{22}$ But there was no indication that the rest of Latin America was ready to follow suit.

For Latin America and all other developing countries, we assign emission targets according to the formulas that have been parameterized so as to fit the countries that have gone before them.

\section{Factors for ensuring “fair" emissions target formulas}

There are four issues that must still be resolved before we can calculate emissions target formulas across all countries: (1) how to determine the magnitude of China's cuts in the first budget period in which it is asked to make cuts below BAU; (2) how to determine cuts in its second budget period for those developed countries which haven't committed to pledges; (3) how to set targets for everyone else, including Latin America (which, in light of its stage of development, should, like Korea, act before China and India), the Middle East/North Africa, Southeast Asia, India/South Asia, and Africa; and (4) how to set targets for everyone, including developed countries, after 2050.

Our general guiding principle for determining the emissions targets once developing countries start cutting below BAU is to ask countries to set targets and make cuts that are analogous to those made by others that have gone before them. We put this

\footnotetext{
22 “Mexico: A Model for Developing Countries," Council on Hemispheric Affairs, August 12, 2009. http://www.coha.org/2009/08/mexico-a-model-for-developing-countries/.
} 
general "fairness" principle into practice by including three factors in the emissions target formulas. These three factors, which are additive (logarithmically), are discussed in detail below.

\section{Progressive Reductions Factor}

The first component is called the Progressive Reductions Factor (PRF) and is based on the progressive pattern of emissions reductions (relative to BAU) that other countries have already committed to, expressed as a function of income per capita. This pattern is illustrated in Figure 1, which comes from the data as they were reported at the time of the Kyoto Conference of Parties. The graph confirms that the emissions cuts agreed to at Kyoto were progressive with respect to income. That is, other things equal, richer countries were asked to make more severe cuts relative to BAU (i.e., the status quo or baseline) in the first period. Specifically, each 1 percent difference in income per capita (measured relative to EU income in 1997), increases a country's abatement obligation by $\gamma$ percent, where the abatement obligation is measured in terms of reductions from BAU (relative to the EU cuts agreed to at Kyoto).

The PRF formula is:

$P R F$ (expressed as country's emissions cuts relative to BAU)

$=\quad$ EU's Kyoto commitment for 2008 relative to its BAU

$+.14 *$ (gap between the country's current income per capita and the EU's income per capita in 2007).

The parameter $(\gamma=0.14)$ comes from ordinary least squares (OLS) regression estimates using the data shown in Figure 1. Different values for the parameter could be chosen if 
the parties to a new agreement wanted to increase or decrease the degree of progressivity of the emissions targets.

Figure 1: Emissions Cuts from BAU Under the Kyoto Protocol Relative to Income

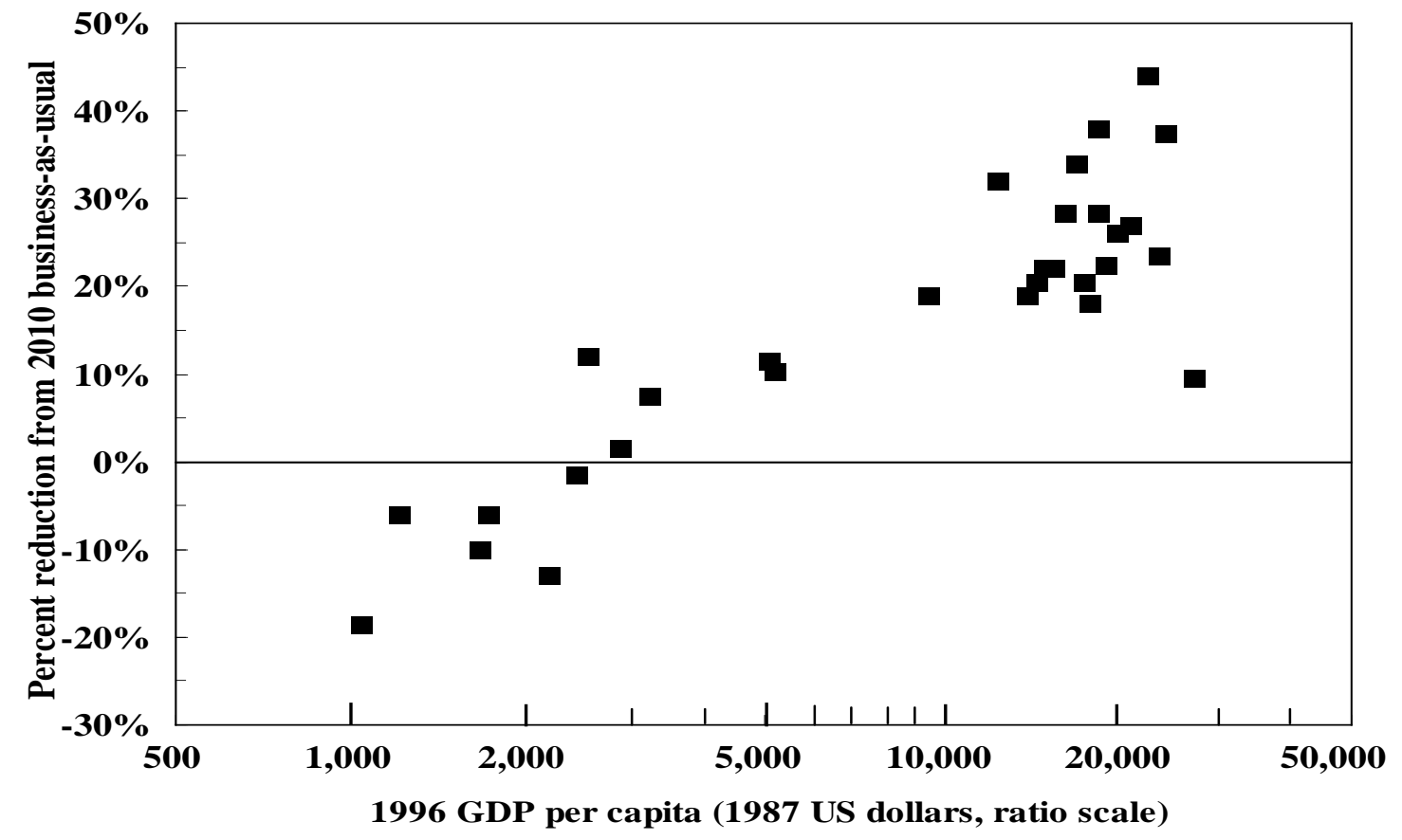

Data Sources: The World Bank, the U.S. Energy Information Administration and country communications with the UNFCCC

We apply this formula to developing countries that agree to accept cuts in the future. Normally, at least in the early budget periods, most developing countries’ incomes will be below the European countries' incomes in 1997, so the PRF dictates milder cuts relative to BAU for developing countries than those made by European countries under Kyoto. In fact, the resulting targets are likely to reflect a "growth path" for developing countries - that is, they will allow for actual emission increases relative to the preceding periods. 


\section{Latecomer Catch-up Factor}

The second "fairness" factor in the formula is the Latecomer Catch-up Factor (LCF). Latecomers are defined as those countries that either have not ratified the Kyoto Protocol or for which Kyoto did not set quantitative targets. These countries should not be rewarded by permanently readjusting their targets to a higher baseline. Aside from notions of fairness, such re-setting of the baseline would give all latecomers an incentive to ramp up their emissions before signing on to binding targets, or, at a minimum, would undercut any socially-conscious incentives they might otherwise introduce to reduce emissions unilaterally in the time period before they join the system. Thus, the LCF is designed to gradually close the gap between the starting point for latecomers and their 1990 emission levels. The LCF requires further percentage cuts in emissions by a country (relative to BAU plus PRF) the more emissions have been allowed to rise above 1990 levels by the time the country joins the agreement. Hence, the LCF parameter indicates the force with which latecomers are pulled back toward their 1990 emissions levels. The factor is given by:

$$
L C F=\alpha-\lambda \log (\text { country's current emissions / country's } 1990 \text { emissions }) \text {, }
$$

At the time the Kyoto Protocol was negotiated, the analogous parameter for Europe was sufficient to pull the EU average below its 1990 level by 2012. However, the countries for which calibrating this formula is most relevant are not European, since the Europeans are not latecomers. Rather, the relevant countries are the United States and Korea, since these are the only countries among those that did not commit to Kyoto targets whose political leaders had by 2009 indicated explicit targets that were acceptable 
in the second budget period. Therefore, in our analysis, the LCF is parameterized according to the numbers implicit in the proposals made by leaders in these two countries. The United States and Korea are used as trend setters; other countries are asked to move gradually in the direction of 1990 emissions at the same speed that these two have before them.

The LCF parameters, which are applied to all latecomers, are chosen so as to match the numbers implicit in the Waxman-Markey bill, which would bring US emissions to 70 percent below 1990 levels by 2050, and the numbers implicit in the Lee proposal to flatten South Korea's emissions over a period beginning in 2008 . In other words, countries are asked to move gradually in the direction of 1990 emissions in the same way as the United States and Korea would have done before them.

Given these two benchmarks, the numerical estimates for the LCF parameters are $\alpha=0.54$ and $\lambda=0.773$. The Latecomer Catch-up Factor thus works out to:

$$
L C F=0.54-0.773 \log \left(\text { country's current emissions / country's } 1990 \text { emissions) }{ }^{23}\right.
$$

In order to come close to achieving our environmental target (460 ppm of CO2 is as close as we can get) without unacceptable economic costs in some countries, we had to sacrifice a little of the simplicity of the LCF equation by adding dummy variables for both the transition economies (TE) and China. Specifically, because the TE experienced emissions in 1990 that were higher than the subsequent trend, whereas China will

\footnotetext{
${ }^{23}$ This catch-up parameter is much stronger than the one used in Frankel (2009). If Korea were to back away from its president's commitment, but some other important middle-income country were to come forward with explicit and specific numerical targets, then the calculation could be redone.
} 
experience extremely high costs due to the projected baseline, we insert special adjustment terms: 0.38 for the TE and -0.13 for China. ${ }^{24}$

\section{Gradual Equalization Factor}

The third "fairness" factor is the Gradual Equalization Factor (GEF). Under our proposal, even though developing countries are not asked to undertake abatement efforts until after the rich countries have begun to act, and they face milder reduction requirements, they are still likely to claim that it is unfair that although the rich countries created the environmental problem, the poor countries will bear a disproportionate share of the costs.

On the one hand, such complaints are not unreasonable. If we were to include only the first two factors in our formula, the richer countries would in effect be granted the permanent right to emit more GHGs than the developing countries, every year in perpetuity. This would be unfair.

On the other hand, calls for rich countries to cut their per capita emissions rapidly in the short run, toward the levels of developing countries, ignore the reality that the economic costs of such a requirement would be so high that no rich country would ever agree to it. However, the situation changes when we look at the longer run (i.e., 50 to 100 years). When countries are given time to adjust, the economic costs are not impossibly high, and it is reasonable to ask rich countries to bear their full share of the burden of emissions reductions. Furthermore, over a time horizon this long, some of the developing countries will likely become high-income countries (and possibly vice versa).

\footnotetext{
${ }^{24}$ This is a departure from our preferred principle of applying the same formula for all countries (as done in Frankel, 2009), a simplification that is appealing both aesthetically and politically. But, as noted above, it is one of the concessions we have to make to attain the more aggressive environmental goal.
} 
Thus, during each decade of the second half of the century, we include an equity factor in the formula, the GEF, that moves per capita emissions in each country a small step toward the global average - downward in the case of the rich countries and upward in the case of the poor countries. Asymptotically, the repeated application of this factor would eventually leave all countries with equal emissions per capita, although corresponding national targets need not necessarily converge fully by $2100{ }^{25}$

The parameter for the speed of adjustment toward the world average was initially chosen to match the rate at which the EU's already-announced goals for 2045-2050 converge to the world average. This number is 0.1 per five-year budget period, which is also very similar to the rate of convergence implicit in the U.S. goals set for the 20452050 period in the Lieberman-Warner legislation. Thus the GEF formula is:

$G E F=-0.1$ (percentage gap between country's lagged emissions per capita and world average emissions per capita).

The global equalization parameter is not set in stone and one could increase the speed towards equal per capita emissions as a way to reach more ambitious environmental targets. This obviously would result in higher costs, especially for countries such as China and the TE.

\footnotetext{
${ }^{25}$ Motivated by a rights-based approach, Zhang (2008) and others propose that countries "contract and converge" to targets that reflect equal emissions per capita. The Greenhouse Development Rights approach of Baer et al. (2008), as extended by Cao (2009), emphasizes, from a philosophical standpoint, the allocation of equal emission rights at the individual level, though these authors appear to recognize that, in practice, individual targets would have to be aggregated and implemented at the national level.
} 


\section{Numerical emissions targets for all countries in all decades}

This section describes the specific numerical emissions targets that were produced by applying the proposed formulas to all countries in all budget periods during this century. Table 1 indicates the years that each of the eleven countries or regional groupings is asked to commit to BAU targets (column 1) and then reductions below BAU (column 2, which shows the year that the PRF and LCF are included in the formulas, and column 3, which shows the year that GEF is added to the formulas). The dates in Table 1 are earlier than those in Frankel (2009) because of this paper's more aggressive environmental goal of $460 \mathrm{ppm}$.

Table 1: Years when participants commit to targets at and below BAU

\begin{tabular}{|c|c|c|c|}
\hline & $\begin{array}{c}\text { First year of commitment } \\
\text { (TARGET or BAU) }\end{array}$ & $\begin{array}{c}\text { First year of commitment to TARGET } \\
\text { (which includes PCF \& LCF) below } \\
\text { BAU }\end{array}$ & $\begin{array}{c}\text { year when GEF is included } \\
\text { in formula }\end{array}$ \\
\hline USA & 2010 & 2010 & 2050 \\
\hline EU & 2010 & 2010 & 2050 \\
\hline KOSAU & 2010 & 2020 & 2050 \\
\hline CAJAZ & 2010 & 2015 & 2050 \\
\hline TE & 2010 & 2025 & 2055 \\
\hline MENA & 2010 & 2025 & 2055 \\
\hline SSA & 2025 & 2050 & 2080 \\
\hline SASIA & 2010 & 2025 & 2055 \\
\hline CHINA & 2010 & 2025 & 2055 \\
\hline EASIA & 2010 & 2025 & 2055 \\
\hline LAM & 2010 & 2020 & 2050 \\
\hline
\end{tabular}

NOTE:

USA $=$ UnitedStates

$E U=$ Western and Eastern Europe CAJAZ = Canada, Japan + New Zealand MENA = Middle East + North Africa $S A S I A=$ India and the rest of South Asia EASIA = Smaller countries of East Asia
KOSAU $=$ Korea, South Africa + Australia (all coal-users)

$T E=$ Russia and other Transition Economies

SSA $=$ Sub-Saharan Africa

CHINA = PRC

$L A M=$ Latin America + the Caribbean 
Table 2: Actual emissions per capita for 11 regions, throughout the century (ton

\section{CO2 per capita)}

\begin{tabular}{|c|c|c|c|c|c|c|c|c|c|c|c|}
\hline & USA & EURO & KOSAU & CAJAZ & $\mathrm{TE}$ & MENA & SSA & SASIA & CHINA & EASIA & LAM \\
\hline 2005 & 20.42 & 8.65 & 11.97 & 11.96 & 7.92 & 4.83 & 0.23 & 0.87 & 4.79 & 1.73 & 3.00 \\
\hline 2010 & 20.76 & 9.10 & 10.96 & 12.39 & 8.54 & 5.26 & 0.27 & 0.91 & 4.89 & 2.08 & 3.24 \\
\hline 2015 & 19.65 & 9.14 & 10.23 & 12.50 & 8.82 & 5.52 & 0.29 & 1.03 & 5.39 & 2.37 & 3.53 \\
\hline 2020 & 18.16 & 8.80 & 9.41 & 12.08 & 8.96 & 5.66 & 0.31 & 1.02 & 5.78 & 2.60 & 3.83 \\
\hline 2025 & 16.52 & 8.25 & 8.60 & 11.39 & 8.71 & 5.35 & 0.32 & 1.01 & 5.33 & 2.65 & 3.89 \\
\hline 2030 & 12.65 & 6.61 & 6.98 & 9.17 & 6.60 & 4.01 & 0.27 & 0.86 & 4.69 & 2.25 & 3.27 \\
\hline 2035 & 10.17 & 5.50 & 5.87 & 7.62 & 5.46 & 3.29 & 0.24 & 0.78 & 4.25 & 1.98 & 2.76 \\
\hline 2040 & 8.62 & 4.80 & 5.14 & 6.60 & 4.84 & 2.92 & 0.23 & 0.74 & 3.99 & 1.84 & 2.58 \\
\hline 2045 & 7.47 & 4.27 & 4.60 & 5.80 & 4.42 & 2.70 & 0.23 & 0.72 & 3.81 & 1.73 & 2.47 \\
\hline 2050 & 6.49 & 3.78 & 4.13 & 5.08 & 4.05 & 2.50 & 0.23 & 0.71 & 3.66 & 1.62 & 2.37 \\
\hline 2055 & 5.67 & 3.36 & 3.74 & 4.45 & 3.92 & 2.35 & 0.22 & 0.70 & 3.52 & 1.52 & 2.28 \\
\hline 2060 & 5.01 & 3.00 & 3.41 & 3.90 & 3.91 & 2.24 & 0.22 & 0.69 & 3.41 & 1.43 & 2.21 \\
\hline 2065 & 4.40 & 2.68 & 3.10 & 3.40 & 3.89 & 2.14 & 0.23 & 0.68 & 3.29 & 1.33 & 2.13 \\
\hline 2070 & 3.82 & 2.40 & 2.82 & 3.08 & 3.88 & 2.04 & 0.23 & 0.66 & 3.16 & 1.22 & 2.04 \\
\hline 2075 & 3.29 & 2.13 & 2.56 & 3.05 & 3.86 & 1.94 & 0.23 & 0.64 & 3.03 & 1.12 & 1.95 \\
\hline 2080 & 2.80 & 1.92 & 2.46 & 3.02 & 3.84 & 1.84 & 0.22 & 0.62 & 2.90 & 1.01 & 1.86 \\
\hline 2085 & 2.33 & 1.89 & 2.45 & 2.99 & 3.82 & 1.74 & 0.22 & 0.60 & 2.76 & 0.90 & 1.75 \\
\hline 2090 & 1.96 & 1.87 & 2.44 & 2.97 & 3.79 & 1.62 & 0.22 & 0.57 & 2.67 & 0.79 & 1.63 \\
\hline 2095 & 1.83 & 1.83 & 2.42 & 2.93 & 3.73 & 1.44 & 0.21 & 0.51 & 2.67 & 0.64 & 1.44 \\
\hline 2100 & 1.68 & 1.78 & 2.41 & 2.88 & 3.65 & 1.29 & 0.20 & 0.45 & 2.70 & 0.57 & 1.22 \\
\hline
\end{tabular}

Table 2 reports projected emissions, expressed in per capita terms, for each country or region in every budget period. The United States is particularly conspicuous in terms of its current high per capita emissions, but its target path begins to decline after 2010. Emissions in all the rich regions decline rapidly between 2020 and 2050 . Emissions in developing countries continue to rise for a bit longer, and then come down more gradually, but of course their per capita emissions start from a much lower base. China peaks in 2020, at 5.8 tons of CO2, or about $1 \frac{1 / 2}{2}$ tons of carbon (C), per capita. However, none of the other developing countries ever gets above 1 ton $\mathrm{C}$ per capita. In contrast, the industrialized countries emit between 8 and 20 tons CO2 (or 2 and 51/2 tons 
C) per capita before they start to cut emissions. In the second half of the century, all of the countries/regions converge to levels below one ton C per capita.

\section{Figure 2:}

Assigned targets and actual emissions for industrialized countries in the aggregate (Note: Predicted actual emissions exceed targets by amount of allowance - or permit purchases.)

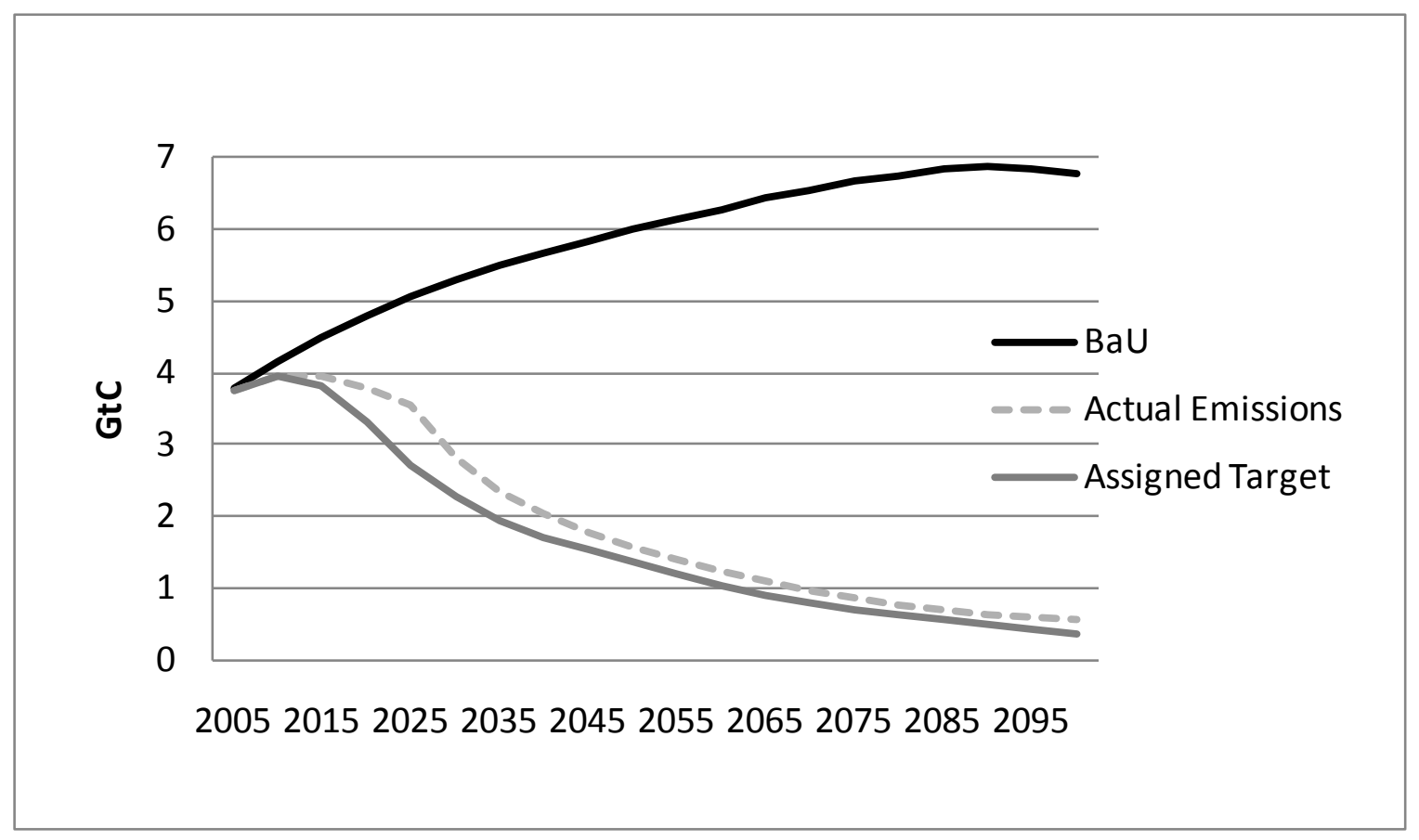

Figure 2 presents the assigned aggregate targets (caps) for member countries of the Organization for Economic Co-operation and Development (OECD). These targets decline from about 4 gigatons (Gt) C in 2020 to 1 Gt C in 2060. The figure also shows the simulated value for actual emissions from OECD countries, which decline more gradually than the targets through 2070 because carbon allowances (permits) are purchased on the world market, as is economically efficient. The total value of the permit purchases is about $1 / 2 \mathrm{Gt} C$ in the middle decades of the century. The quantity of permits purchased by the OECD countries is generally less than one fifth of their total 
reductions, with the US being the largest buyer. This is a far smaller trading share than Frankel (2009) entailed, due to the tougher targets assigned to the developing countries under the current plan. In addition, legislation in both Brussels and Washington places limits on the amount of emissions reductions that can be achieved through permit purchases. The trading share falls off sharply in the second half of the century.

Figure 3: Assigned targets and actual emissions for non-OECD countries in the aggregate

(Note: Predicted actual emissions fall below caps by amount of permit sales )

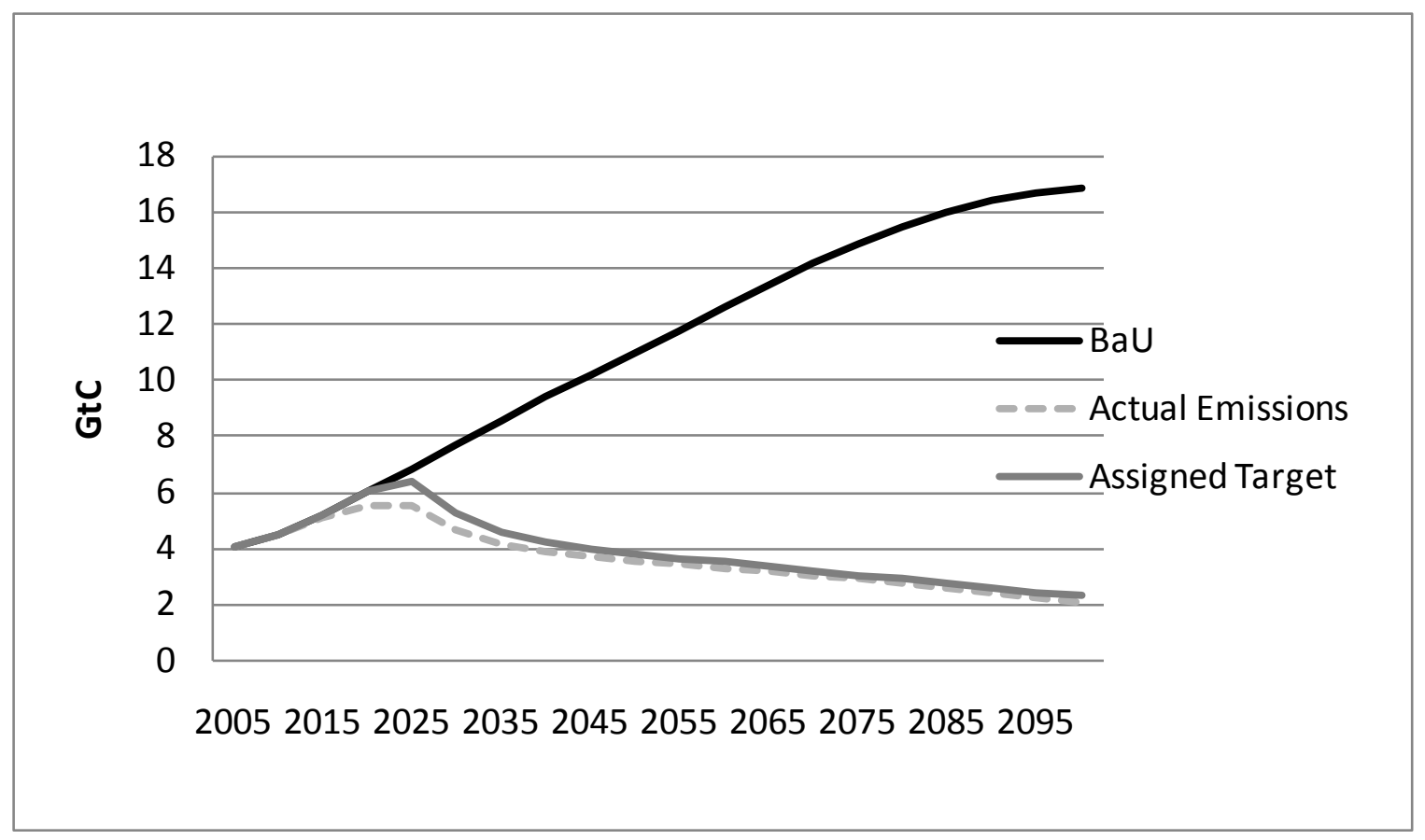

Concerning the non-OECD countries, emissions peak in 2020 in the TE group, MENA, China, and Latin America, but in sub-Saharan Africa, emissions remain at very low levels throughout the century. Figure 3 shows that among non-OECD countries overall, both emissions targets and actual emissions peak in 2020. The simulated path of actual emissions lies a little above the target caps, again due to the value of permits sold 
by the developing countries to the industrialized countries. Total emissions for non-

OECD countries fall to $2 \mathrm{Gt} C$ at the beginning of the $22^{\text {nd }}$ century.

Total world emissions peak in 2020 below $10 \mathrm{Gt}$ C, as shown in Figure 4.

Figure 4: Global emissions in the BaU and under the Assigned Targets

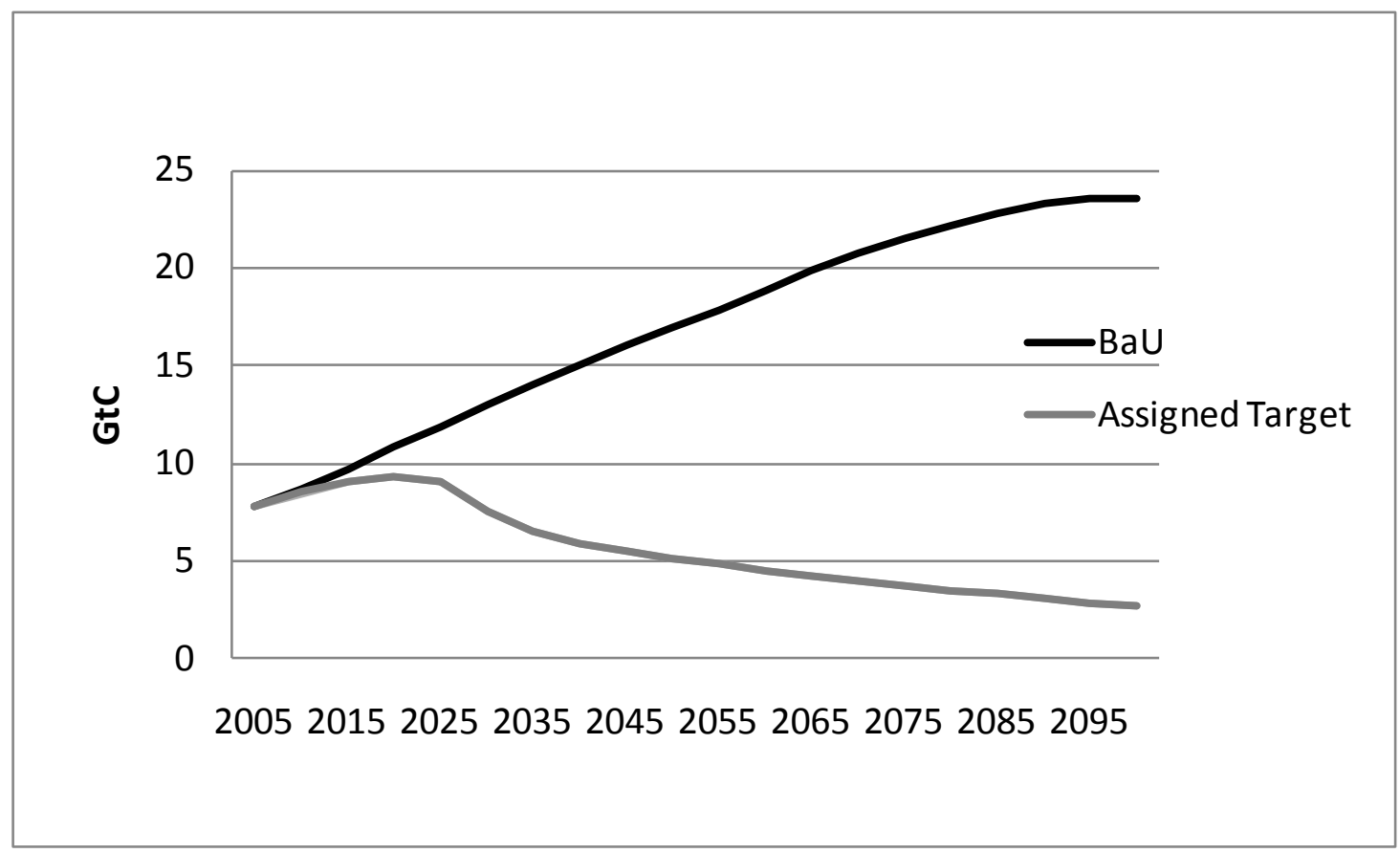

\section{Economic and environmental consequences of the proposed targets}

Estimating the economic and environmental implications of any set of targets is a complex task. $^{26}$ This section discusses the economic and environmental consequences

\footnotetext{
${ }^{26}$ Researchers have applied a number of different models to estimate the economic and environmental effects of various specific proposed emission paths; see, for example, Edmonds, Pitcher, Barns, Baron, and Wise (1992); Edmonds, Kim, McCracken, Sands, and Wise (1997); Hammett (1999); Manne, Mendelsohn, and Richels (1995); Manne and Richels (1997); McKibbin and Wilcoxen (2007); and Nordhaus (1994, 2008). Weyant (2001) provides an explanation and comparison of different models.
} 
of the numerical emissions targets proposed here, as estimated by the WITCH model, which has been used extensively in the past five years to analyze the economic impacts of climate change policies. WITCH is a hybrid top-down economic model with energy sector disaggregation. ${ }^{27}$ Those who might be skeptical of economists' models on the grounds that "technology is the answer" should rest assured that technology is central to this model, as it features endogenous technological change via both experience and innovation processes. Countries are grouped into twelve regions (with Western Europe and Eastern Europe grouped separately) that cover the world and that interact strategically following a game theoretic set-up.

The original baselines in many models have been deflected in recent years by such developments as stronger-than-expected growth in Chinese energy demand and the 2008 spike in world oil prices. Accordingly, the WITCH model has been updated with more recent data, and projections have been revised for key drivers such as population, GDP, fuel prices, and energy technology characteristics. The base calibration year has been set at 2005, for which data on socio-economic, energy, and environmental variables are available (Bosetti, De Cian, Sgobbi, and Tavoni, 2009b).

\section{Economic effects}

Although economists trained in benefit-cost analysis tend to focus on economic costs expressed in terms of income, those who are politically attuned tend to focus also on the predicted carbon price, which in turn has a direct impact on the prices of gasoline, home heating oil, and electric power. The WITCH model estimates that the price of $\mathrm{CO}_{2}$

\footnotetext{
27 The model and its detailed structure are described in Bosetti et al. (2006) and Bosetti, Massetti, and Tavoni (2007).
} 
that would result under the proposed targets rises very substantially, reaching $\$ 1800$ per ton in 2100, see Figure 5. This is a high number, approximately twice the CO2 price with an environmental goal of $500 \mathrm{ppm}$. At least the called for rise is monotonic during the course of the century, however, which is a desirable property.

\section{Figure 5: Price of Carbon Dioxide Rises Steadily Over the Century}

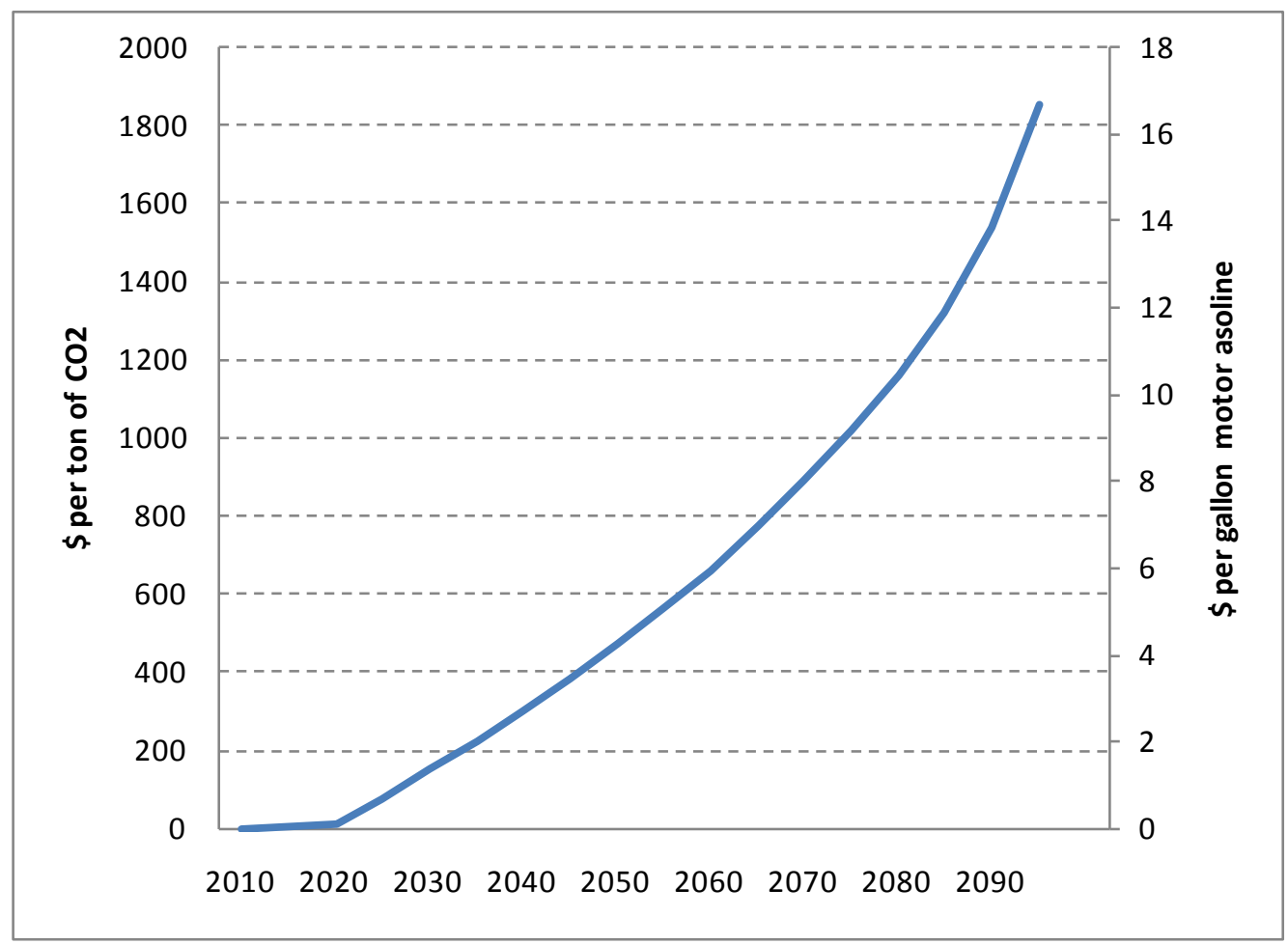

The right margin of the graph translates the cost from dollars per ton of carbon to terms that the American consumer can relate to: the increment to the cost of gasoline. It rises to European levels by 2040, and to \$16 per gallon in 2100 . 
Economic losses by region, measured in terms of national income, are illustrated for the first and second halves of the century in Figure 6a and 6b, respectively. ${ }^{28}$ These losses also rise gradually. This is a good outcome, because a positive rate of time discount means that losses come later count less than losses that come earlier. As late as 2055, all regions sustain economic losses that are no greater than 3.5 per cent of income. ${ }^{29}$ However, later in the century, the costs go much higher, above 11 percent of income in the case of TE and China. The costs estimated here, using the WITCH model, are broadly in line with those estimated by a range of other leading models, as summarized in Clarke, et al (2009).

In one sense, the costs of participation in the proposed framework are overestimated, increasingly so in the later decades, if the alternative to participating in the treaty for one more decade is dropping out after seven or eight decades of participation. The reason is that countries will have already substantially altered their capital stocks and economic structures in a carbon-friendly direction. The economic costs reported in the simulations and graphs treat the alternative to participation as having never joined the treaty in the first place. In another sense, however, the costs are underestimated, because any country that drops out can exploit leakage opportunities, as its firms are able to buy fossil fuels at far lower prices than their competitors in countries that continue to participate.

\footnotetext{
${ }^{28}$ The graphs in the working paper show emissions targets in 5-year intervals. Here they have been aggregated into 10-year intervals for easier visibility.

${ }^{29}$ As of mid-century, the US is running the largest cost among OECD countries, relative to BAU, and MENA and China are running the largest costs among non-OECD countries.
} 
Figure 6: Income Losses by Region and Period (negative values are gains)

a) $2010-2045$

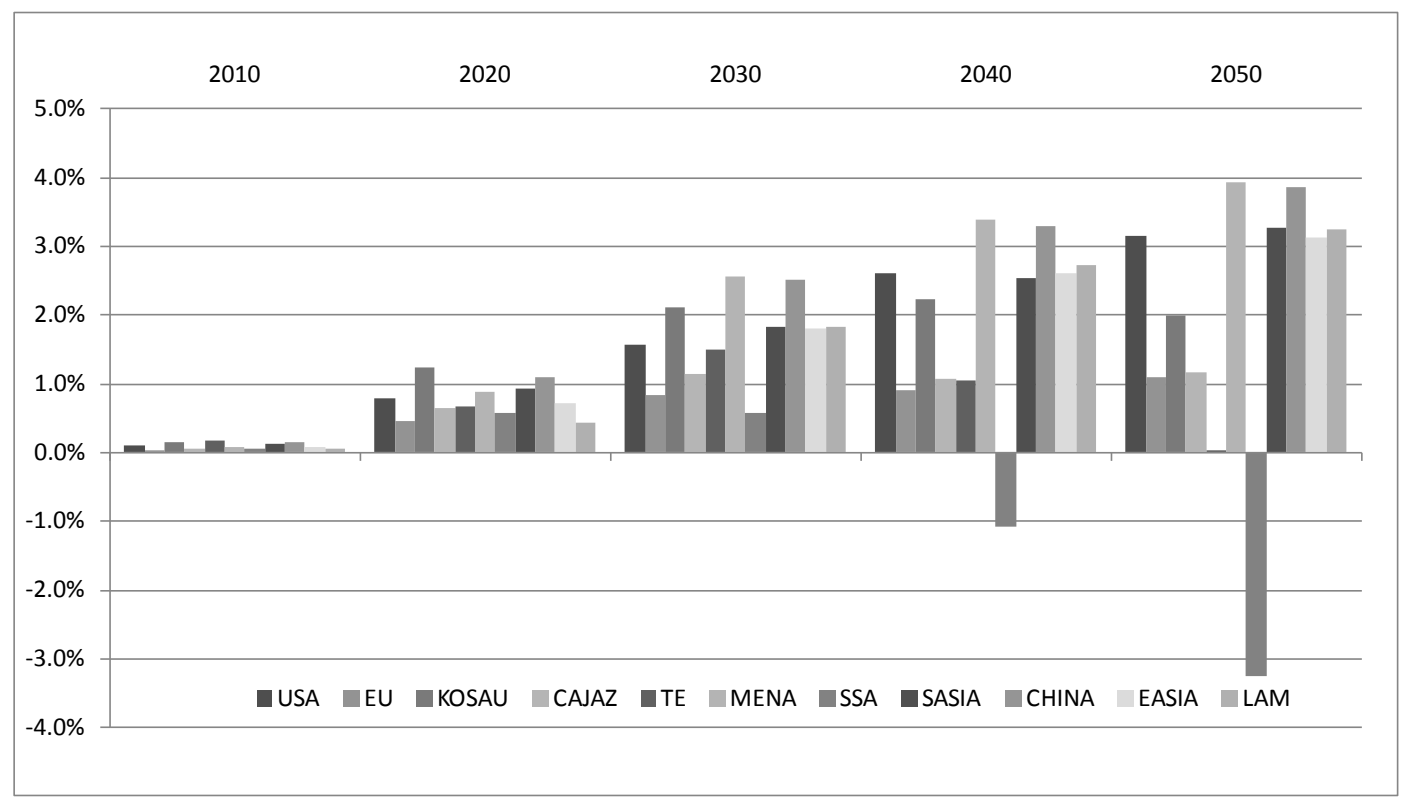

b) 2050- 2100

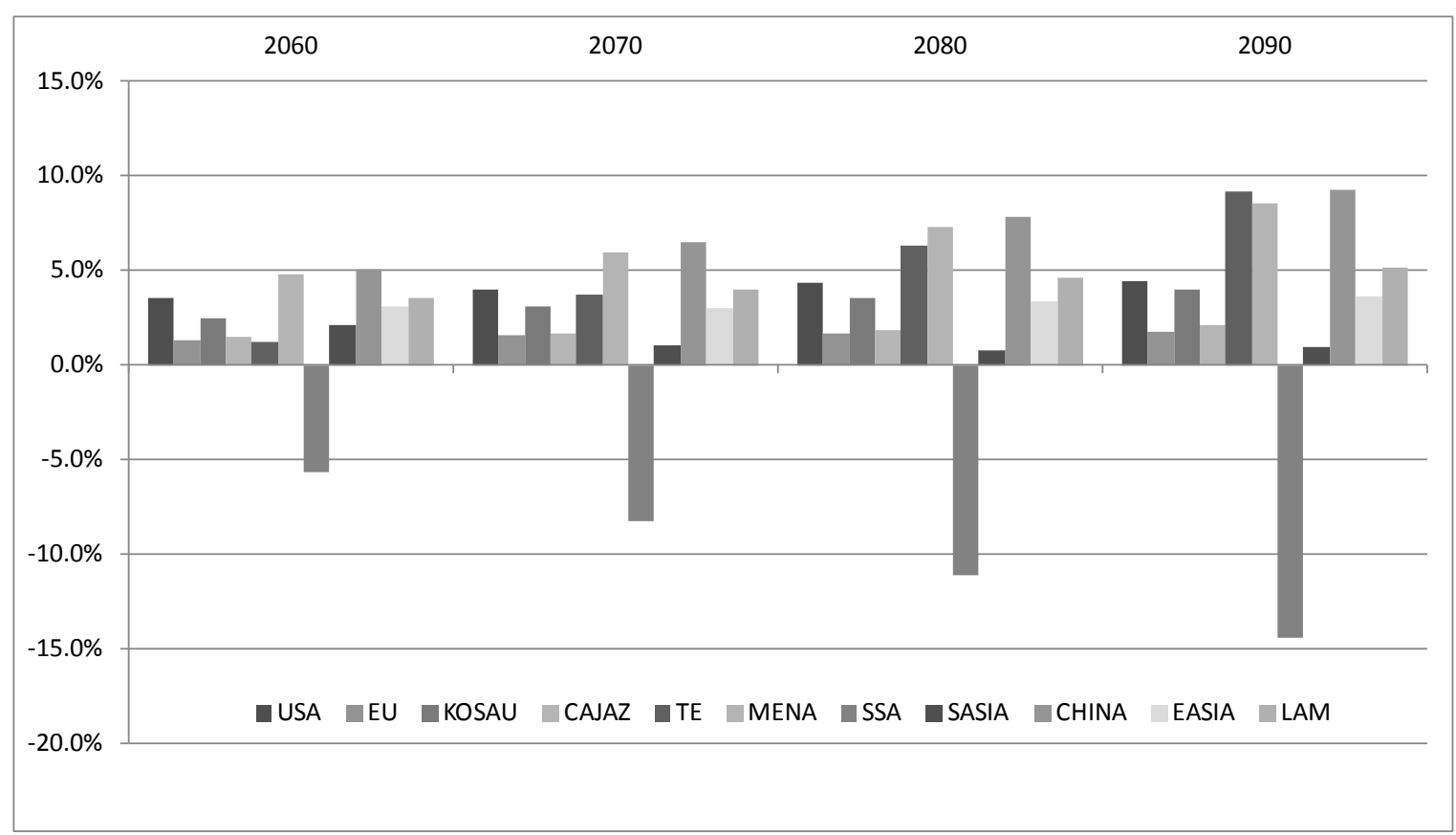


After 2065, the combination of parameters yields costs that rise above our selfimposed threshold of 5 percent of national income, a consequence of the more aggressive environmental goal. All economic effects are deliberately gross of environmental benefits - that is, no attempt is made to estimate environmental benefits or net them out.

We measure the present discounted value (PDV) of costs using a discount rate of 5 percent. Total economic costs are estimated to be 1.39 percent of annual gross world product. The discounted economic costs by region are presented in Figure 7, and range from over 3\% benefit accruing to Sun Saharan Africa, gaining from selling emission allowances to the rest of the world, to the losses larger than $2 \%$ accruing to the TE and China.

The more conventional approach would be to choose country targets with no constraint beyond minimizing the PDV of country costs. We believe that our contribution is the simplicity of a common formula across countries and across time, the constraint that no country endures an unusually high cost in any single period, and the correspondingly enhanced credibility. Nevertheless, we have explored what happens if we jettison the formulas and simply choose country targets so as to minimize the threshold for PDV of country costs. The outcome: the gain from the reduced PDV of losses is small, on the order of $1 / 10$ of one percent of GDP, relative to the results of our formulas approach.

Figure 7: Economic Costs of Emissions Targets by Region, 2010-2100, as a percentage of GDP (negative values are gains) 


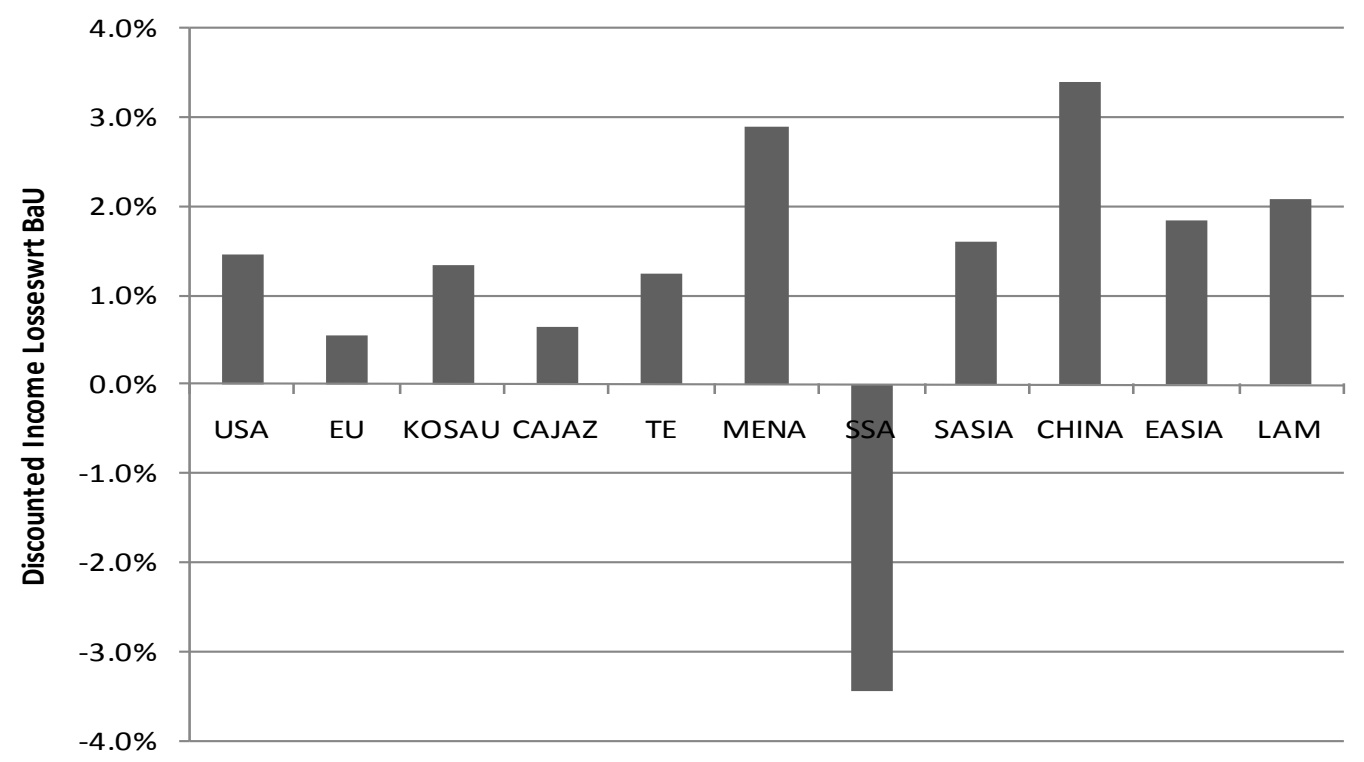

Note: Costs are discounted to 2005 using a 5\% discount rate.

\section{Environmental effects}

Under the emissions numbers produced by this proposal, the concentration of $\mathrm{CO}_{2}$ in the atmosphere is projected to reach $460 \mathrm{ppm}$ in the latter half of the century (see Figure 8). Based on the modeled trajectory of concentrations, the rise in global average temperature above pre-industrial levels is projected to be less than 2.8 degrees Celsius $\left({ }^{\circ} \mathrm{C}\right)$ at the end of the century, versus almost $4{ }^{\circ} \mathrm{C}^{30}$ under the BAU trajectory (see Figure 9). The result is less ambitious than the goal of stabilizing the temperature increase below $2{ }^{\circ} \mathrm{C}$, set by the G-8 leaders at their 2009 summit. The very modest reduction in temperature that results from increasingly stringent climate policies may be disappointing to some. However, it is due to nonlinearity: a $1 \%$ decrease in $\mathrm{CO}_{2}$ concentrations

\footnotetext{
${ }^{30}$ Temperature projections have always to be considered as best guesses. Large uncertainties affecting the carbon cycle and climate feedbacks could alter the true result in term of temperature increase.
} 
translates to less than a $1 \%$ decrease in global warming. Policies aimed at reducing emissions from land use and other greenhouse gasses could enhance the impact of the policy on final temperature.

Figure 8: Path of $\mathrm{CO}_{2}$ concentrations that achieves year-2100 goal of $460 \mathrm{ppm}$

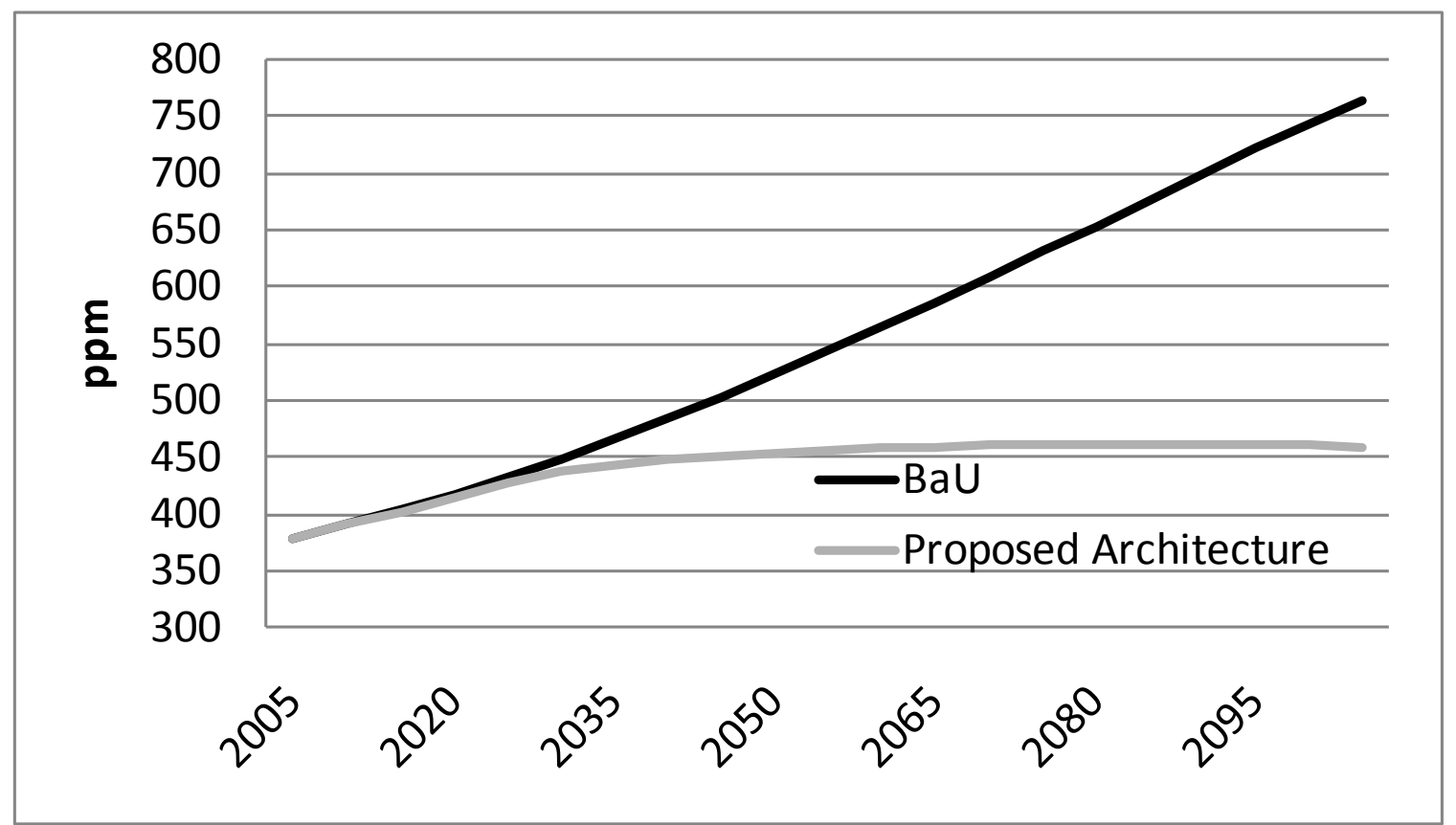

Figure 9: Rise in temperature under proposed targets vs. BAU 


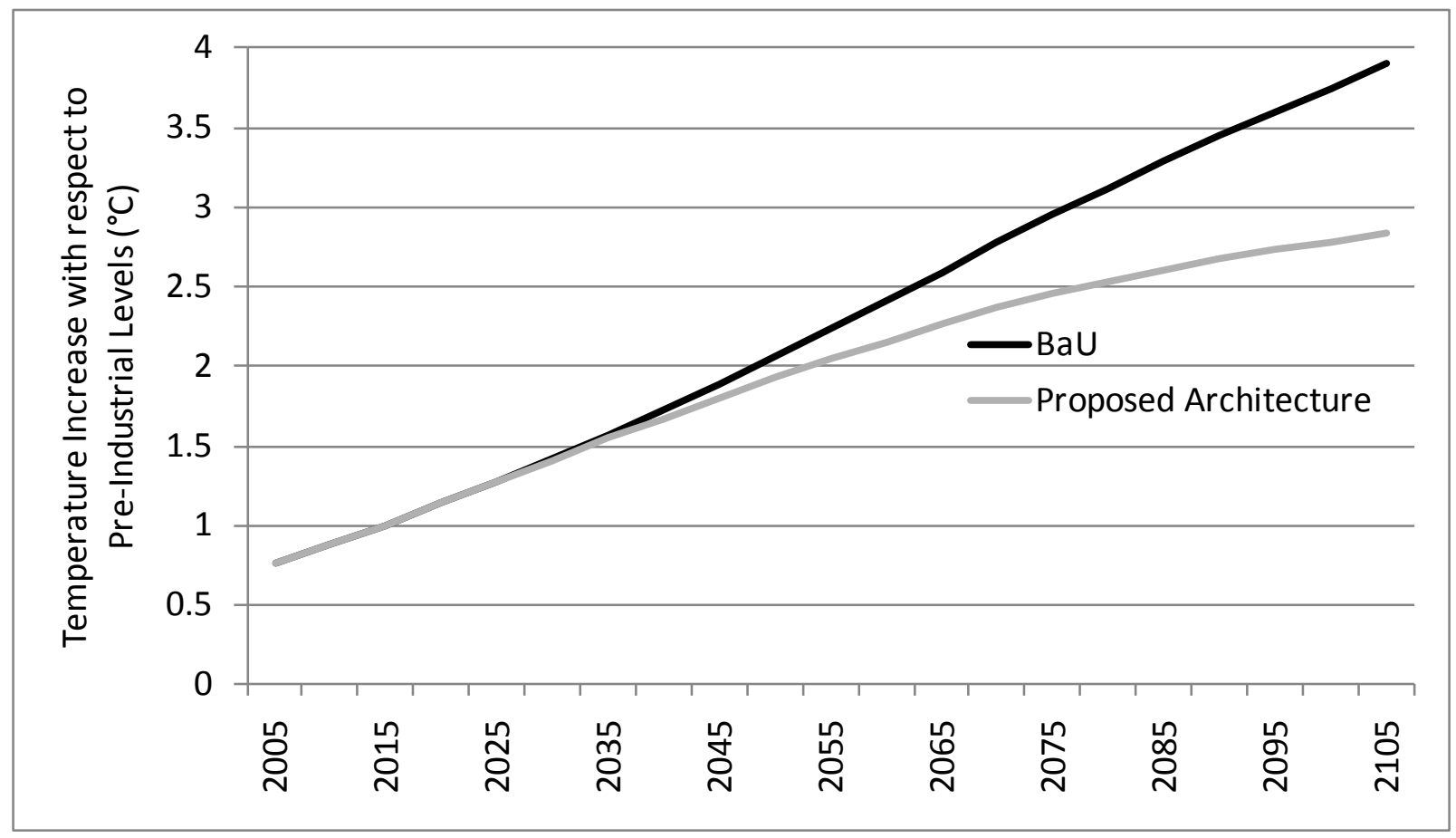

\section{Conclusions}

Some readers may conclude that the results above suggest that more ambitious environmental goals of $460 \mathrm{ppm}$ in $\mathrm{CO} 2$ concentrations are not attainable in practice, and that our earlier proposal for attaining 500 ppm (Frankel, 2009) is the better plan. We take no position on which environmental goal is best overall. Rather, we argue that whatever the environmental goal, our approach will give targets that are more practical, both economically and politically, than the approaches that have been proposed by others.

\section{A politically credible framework}

The framework presented here specifies the allocation of emissions targets across countries in a way that gives every country reason to believe that it is only doing its fair 
share and that builds trust as the decades pass. Without such a framework, announcements of distant future goals will not be credible and thus will not have the desired effects. Furthermore, this framework - in providing for a decade-by-decade sequence of emissions targets, each determined on the basis of a few principles and formulas - is flexible enough that, by small changes in the formula parameters, it can accommodate major changes in economic, environmental, political, or technological circumstances during the course of the century.

\section{Directions for future research}

We have identified several directions for extending our research in the future.

First, we could compare our proposed set of emissions paths to other proposals being discussed in the climate change policy community or being analyzed using other integrated assessment models. ${ }^{31}$ Our conjecture is that we could identify countries and periods in alternative pathways where an agreement would be unlikely to last because its targets were not designed to limit economic costs for each country.

Second, we could take into account GHGs other than $\mathrm{CO}_{2}$ and allow for other mitigation measures such as forestation, updating them to reflect the outcome of ongoing negotiations.

Third, we could implement constraints on international trading. Such constraints can arise either from a philosophical worldview that considers it unethical to pay others to take one's medicine, or from a more cynical worldview that assumes international

\footnotetext{
${ }^{31}$ For example, the CLEAR path offered by Wagner et al. (2008) proposes that by 2050 Russia has cut its emissions 30 percent below 1990 levels, China 46 percent below 2012 levels, India 8 percent above 2012 levels, and the other non-Annex I countries 23 percent below 2012 levels. The Global Development Rights approach of Baer et al. (2008) proposes a US emissions target for 2025 that is 99 percent below its BAU path.
} 
transfers via permit sales will only line the pockets of corrupt leaders. Constraints on trading could take the form of quantity restrictions - for example, that a country cannot satisfy more than $Z$ percent of its emissions obligation through international permit purchases.

The fourth possible extension of this research represents the most important step intellectually: to introduce uncertainty, that is, to allow for rates of economic growth or technological progress that turn out to be higher or lower than was forecast in the BAU path. We would show the consequences of our rule that if any country makes an ex post determination in any period that by staying in the treaty it loses more than $\mathrm{X}$ percent of income, even though this had not been the expectation ex ante, that country will drop out. One benefit of this exercise would be to assure those who believe that the costs are likely eventually to be lower (or higher) than implied by the WITCH model that the target formulas could be adjusted accordingly, as the truth is revealed, while staying within the framework.

The ultimate objective in making the model stochastic would be to show that the general policy framework is relatively robust with respect to unexpected developments and to seek modifications of the formulas to produce a version that is still more robust. Formulas should be set so as to protect against inadvertent stringency on the one hand that is, a situation where the cost burden imposed on a particular country is much higher than expected - or inadvertent "hot air" on the other. ${ }^{32}$

Three possible modifications for dealing with uncertainty are promising. First, we should allow for renegotiation of parameters along the way if there are unexpected

\footnotetext{
32 "Hot air" refers to the possibility that targets are based on obsolete emissions levels with the result that countries are credited for cutting tons of emissions that would not have been emitted anyway.
} 
developments in the future. Second, when the target for each decade is set, it should be indexed to GDP within that budget period. Perhaps the constant of proportionality in the indexation formula would simply equal 1 , in which case it becomes an efficiency target, expressed in carbon emissions per unit of GDP. This approach would be much less vulnerable to within-decade uncertainty (Lutter, 2000). A third possible feature that would make the policy more robust and that is favored by many economists is an escape clause or safety valve that would limit costs in the event that mitigation proves more expensive than expected, perhaps with a symmetric floor on the price of carbon in addition to the usual ceiling. 


\section{References}

Aldy, Joseph, Scott Barrett, and Robert Stavins, 2003, "Thirteen Plus One: A Comparison of Global Climate Architectures,” Climate Policy, 3, no. 4, 373-97.

--- and Jeffrey Frankel, 2004, "Designing a Regime of Emission Commitments for Developing Countries that is Cost-Effective and Equitable," G20 Leaders and Climate Change, Council on Foreign Relations.

--- , Peter Orszag, and Joseph Stiglitz, 2001, "Climate Change: An Agenda for Global Collective Action." The Pew Center Workshop on the Timing of Climate Change Policies. October.

Baer, Paul, Tom Athanasiou, Sivan Kartha and Eric Kemp-Benedict, 2008, The Greenhouse Development Rights Framework: The Right to Development in a Climate Constrained World (Hendrich Boll Stiftung, Stockholm, $2^{\text {nd }}$ edition).

Barrett, Scott, 2006, “Climate Treaties and 'Breakthrough' Technologies,” American Economic Review, vol. 96, no. 2, May, 22-25.

Bosetti, V., C. Carraro, M. Galeotti, E. Massetti and M. Tavoni, 2006, "WITCH: A World Induced Technical Change Hybrid Model.” The Energy Journal, pp. 13-38.

---, C. Carraro, A. Sgobbi, and M. Tavoni, 2009, “Modelling Economic Impacts of Alternative International Climate Policy Architectures: A Quantitative and Comparative Assessment of Architectures for Agreement," in Joseph Aldy and Robert Stavins, eds., Post-Kyoto International Climate Policy. (Cambridge, UK: Cambridge University Press).

---, E. De Cian, A. Sgobbi, M. Tavoni, 2009b, "The 2008 WITCH Model: New Model Features and Baseline," Working paper no. 85 (Fondazione Eni Enrico Mattei: Milan).

---, and Jeffrey Frankel, 2009, “Global Climate Policy Architecture and Political Feasibility: Specific Formulas and Emission Targets to Attain 460 ppm CO2 Concentrations,” FEEM Working Paper 92 and NBER Working Paper 15516.

--- , E. Massetti and M. Tavoni, 2007, “The WITCH Model. Structure, Baseline, Solutions”. FEEM Working Paper no. 10.

Cao, Jing, 2009, "Reconciling Human Development and Climate Protection: Perspectives from Developing Countries on Post-2012 International Climate Change Policy," in Post-Kyoto International Climate Policy, edited by Joe Aldy and Rob Stavins (Cambridge University Press: Cambridge, UK).

Cao, Jing, 2012, "Beyond Cancun: Reconciling Fairness, Development and Climate Protection,” Review of Environmental Economics and Policy. [Typesetter - please insert correct citation information; this article is part of the same symposium]

Clarke, Leon, Jae Edmonds, Volker Krey, Richard Richels, Steven Rose, Massimo Tavoni, 2009, "International climate policy architectures: Overview of the EMF 22 International Scenarios," Energy Economics 31, S64-S81. 
Edmonds, J.A., H.M. Pitcher, D. Barns, R. Baron, and M.A. Wise, 1992, "Modeling Future Greenhouse Gas Emissions: The Second Generation Model," in Modeling Global Climate Change, Lawrence Klein and Fu-chen Lo, editors (United Nations University Press: Tokyo), pp. 295-340.

--- S.H. Kim, C.N.McCracken, R.D. Sands, and M.A. Wise, 1997, "Return to 1990: The Cost of Mitigating United States Carbon Emission in the Post-2000 Period,” October, Pacific Northwest National Laboratory.

Ellerman, Denny, and Barbara Buchner, 2008, "Over-Allocation or Abatement? A Prelminary Analysis of the EU ETS Based on the 2005-06 Emissions Data," Environmental and Resource Economics 41, no. 2, October, pp. 267-287.

Frankel, Jeffrey, 1999, “Greenhouse Gas Emissions,” Policy Brief no.52, Brookings Institution, Washington, DC.

--- 2005, "You're Getting Warmer: The Most Feasible Path for Addressing Global Climate Change Does Run Through Kyoto," in Trade and Environment: Theory and Policy in the Context of EU Enlargement and Transition Economies, edited J.Maxwell and R.Reuveny (Edward Elgar Publishers, UK).

--- 2007, "Formulas for Quantitative Emission Targets," in Architectures for Agreement: Addressing Global Climate Change in the Post Kyoto World, J.Aldy and R. Stavins, eds. (Cambridge University Press).

--- , 2009, “An Elaborated Proposal For Global Climate Policy Architecture: Specific Formulas and Emission Targets for All Countries in All Decades," in Post-Kyoto International Climate Policy, edited by Joe Aldy and Rob Stavins (Cambridge University Press). NBER WP 18476.

Gore, Al, 1993, Earth in the Balance (Penguin Books, New York).

Hammett, James, 1999, "Evaluation Endpoints and Climate Policy: Atmospheric Stabilization, Benefit-Cost Analysis, and Near-Term Greenhouse Gas Emissions,” Climatic Change 41: 447468.

Lutter, Randy, 2000, “Developing Countries’ Greenhouse Emissions: Uncertainty and Implications for Participation in the Kyoto Protocol,” Energy Journal 21(4): 93-120.

Manne, Alan, Robert Mendelsohn, Richard Richels, 1995, "MERGE: A Model for Evaluating Regional and Global Effects of GHG Reduction Policies," Energy Policy 23:17.

--- and Richard Richels, 1997, “On Stabilizing CO2 Concentrations - Cost-Effective Emission Reduction Strategies,” Stanford University and Electric Power Research Institute, April.

McKibbin, Warwick, and Peter Wilcoxen, 2007, "A Credible Foundation for Long Term International Cooperation on Climate Change," in Architectures for Agreement: Addressing Global Climate Change in the Post-Kyoto World, edited by Joseph Aldy and Robert Stavins, Cambridge University Press. 
Metcalf, Gilbert E., and David Weisbach, 2012, "Linking Policies When Tastes Differ: Global Climate Policy in a Heterogeneous World," Review of Environmental Economics and Policy. [Typesetter - please insert correct citation information; this article is part of the same symposium]

Nordhaus, William, 1994, Managing the Global Commons: The Economics of Climate Change, MIT Press: Cambridge.

--- 2006, “Life After Kyoto: Alternative Approaches Global Warming Policies,” American Economic Review, Papers and Proceedings, vol. 96, no. 2, May: 31-34.

--- 2008, A Question of Balance: Weighing the Options on Global Warming Policies (Yale University Press).

Olmstead, Sheila, and Robert Stavins, 2006, "An International Policy Architecture for the PostKyoto Era,” American Economic Review, Papers and Proceedings, vol. 96, no. 2, May: 35-38.

Olmstead, Sheila M., and Robert N. Stavins. 2012, "Three Key Elements of Post-2012 International Climate Policy Architecture," Review of Environmental Economics and Policy. [Typesetter - please insert correct citation information; this article is part of the same symposium]

Pizer, William, 2006, “The Evolution of a Global Climate Change Agreement," American Economic Review, Papers and Proceedings, vol.96, no.2, May, 26-30.

Stewart, Richard, and Jonathan Weiner, 2003, Reconstructing Climate Policy: Beyond Kyoto (American Enterprise Institute Press, Washington DC).

Victor, David, 2004, Climate Change: Debating America's Policy Options (Council on Foreign Relations, New York).

Wagner, Gernot, James Wang, Stanislas de Margerie and Daniel Dudek, 2008, "The CLEAR Path: How to Ensure that if Developing Nations Adopt Carbon Limits, Their Early Actions Will be Rewarded,” Environmental Defense Fund Working Paper, October 30.

Weyant, John, 2001, "Economic Models: How They Work \& Why Their Results Differ." In Climate Change: Science, Strategies, \& Solutions. Eileen Claussen, Vicki Arroyo Cochran, and Debra Davis, editors (Brill Academic Press, Leiden), pp. 193-208.

Wigley, Tom M.L., Rich G. Richels and Jae A. Edmonds, 2007, “Overshoot Pathways to CO2 Stabilization in Multi-GasContext,” in Human-induced climate change: An interdisciplinary assessment (Cambridge University Press), edited by RG Richels, AS Manne, and TML Wigley, Chapter 32, pp. 387-401.

Zhang, Yongsheng, 2008, “An Analytical Framework and Proposal to Succeed Kyoto Protocol: A Chinese Perspective,” Development Research Center of the State Council, China, Dec. 